\title{
Assessment of serum Aspergillus galactomannan expression and associated risk factors among patients living with HIV at llorin, Nigeria
}

\author{
Hafeez Aderinsayo Adekola, ${ }^{1}$ Olajide Olubunmi Agbede ${ }^{1}$, Idris Nasir Abdullahi, ${ }^{2}$ Lawal O. Olayemi, ${ }^{3}$ \\ Anthony Uchenna Emeribe, ${ }^{4}$ Amos Dangana, ${ }^{5}$ Thairu Yunusa ${ }^{6}$
}

${ }^{1}$ Department of Medical Microbiology and Parasitology, Faculty of Basic Medical Sciences, University of Ilorin, Nigeria; ${ }^{2}$ Department of Medical Laboratory Science, Faculty of Allied Health Sciences, Ahmadu Bello University, Zaria, Nigeria; ${ }^{3}$ Department of Medicine, National University of Samoa, Samoa; ${ }^{4}$ Department of Medical Laboratory Science, University of Calabar, Nigeria; ${ }^{5}$ Department of Medical Laboratory Services, University of Abuja Teaching Hospital, Gwagwalada, Abuja, Nigeria; ${ }^{6}$ Department of Medical Microbiology and Parasitology, University of Abuja, Nigeria

\section{Summary}

Invasive pulmonary aspergillosis still constitutes a diagnostic challenge for clinicians due to its non-specific symptoms. HIV infection represents one of the major risk factors due to the progressive failure of the immune system. In this study, Aspergillus serum galactomannan enzyme linked immunosorbent assay was used for the diagnosis of invasive pulmonary aspergillosis in patients living with HIV/AIDS attending University of Ilorin Teaching Hospital Antiretroviral Therapy Clinic, Nigeria. Blood samples were collected from 97 patients affected by HIV/AIDS. Age range of the study population was between 0 and 79 years. Length of the study: 3 weeks. Three out of the 97 samples were positive for the galactomannan assay with an optical density index of 1.1, 0.9 and 1.1

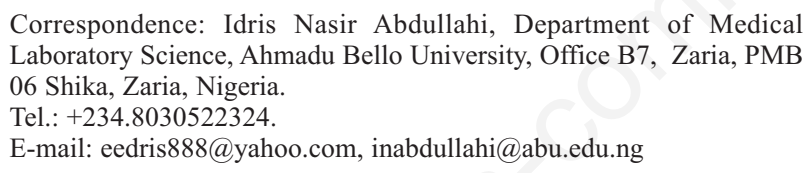

Key words: Pulmonary Aspergillosis, HIV co-infection, Mycosis, Immunosuppression.

Acknowledgements: the authors thank the staff of medical microbiology laboratory, University of Ilorin Teaching Hospital, for their technical input and logistical support.

Contributions: the authors contributed equally.

Conflict of interest: the authors declare no potential conflict of interest.

Funding: none.

Received for publication: 9 March 2019.

Revision received: 3 June 2019.

Accepted for publication: 23 July 2019.

COCopyright: the Author(s), 2019

Licensee PAGEPress, Italy

Microbiologia Medica 2019; 34:8158

doi:10.4081/mm.2019.8158

This article is distributed under the terms of the Creative Commons Attribution Noncommercial License (by-nc 4.0) which permits any noncommercial use, distribution, and reproduction in any medium, provided the original author(s) and source are credited. using the 0.5 cut-off optical density value; the concentration level of galactomannan antigen was therefore $2.20 \mu \mathrm{g} / \mathrm{L}, 1 \mu \mathrm{g} / \mathrm{L}$ and 2.19 $\mu \mathrm{g} / \mathrm{L}$, respectively. A prevalence of $3.1 \%$ (3/97) was detected; all positive participants have been on ART for more than 3 years $(\mathrm{P}<0.0001)$, and 2 out of the 3 had CD4 count higher than 200 cells/mm3 $(\mathrm{P}<0.0001)$. Serum Aspergillus galactomannan assay is less invasive for patients and diagnosis can be made in a relatively shorter time compared to other techniques used in diagnosing invasive pulmonary aspergillosis.

\section{Introduction}

Invasive pulmonary aspergillosis (IPA) is a life-threatening disease condition found in immunocompromised patients. In past years it had been associated with high mortality (1). Global prevalence of the disease is rising due to an increase in number of immunocompromised patients and also as a result of the widespread application of chemotherapy and immunosuppressive agents (2).

Clinical manifestations of the disease include fever, non-productive cough, dyspnoea, haemoptysis and pleuritic chest pain. Additional symptoms, such as swollen eye, nose bleeding, difficulty in talking, facial muscle paralysis, mouth and chest wall ulcers can occur in severe cases of the disease $(1,3)$. IPA clinical manifestations are non-specific because of its similarity with other pulmonary diseases, such as tuberculosis. This complicates diagnosis, as a delay in diagnosis prolongs suffering and promotes dissemination of the disease, thus making it a high public health concern and an economic burden (4).

Galactomannan is a serologically active polysaccharide, which is primarily an important component of cell wall of mould-like fungi particularly in Aspergillus species, but can also be found in other fungi species (5). Galactomannan is a family of molecules containing galactofuranose antigens which are released by fungal species during invasion as a consequence of hyphal tip growth and mycelial breakdown, that can be detected in sera using enzyme linked immunosorbent assay as approved by the United States Food and Drug Administration (FDA) in 2003 (6). The detection of galactomannan is a useful tool in the early diagnosis of invasive fungal infections, particularly invasive pulmonary aspergillosis (7).

The Enzyme Linked Immunosorbent Assay (ELISA) incorporating $\beta 1$-5 galactofuranose-specific EBA2 monoclonal antibody directed against galactomannan, acting as both the detector and acceptor of galactomannan, has been developed showing a high sensitivity (with 
0.5 threshold dose index) in serum samples within 4 hours, a period short enough to provide results to attending physicians managing the disease (8). Galactomannan can also be detected in other biologic fluids, such as bronchoalveolar lavage fluid and urine (9).

Early detection of Aspergillus galactomannan may aid diagnosis and management of invasive pulmonary aspergillosis in patients living with HIV/AIDS, thus improving disease conditions and reducing mortality associated with the disease.

\section{Materials and Methods}

\section{Study area}

This study was carried out at the Department of Medical Microbiology and Parasitology of the University of Ilorin Teaching Hospital (UITH), Ilorin. UITH belongs to the second generation of Teaching Hospitals in Nigeria. It is a tertiary health care centre and the only referral centre in Kwara State with a capacity of over 450 beds and an average of 10,000 to 12,000 annual admissions of in-and outpatients visits, respectively, in the last five years as reported by UITH Department of Health Information Management, 2015. It is located in the North central region of Nigeria. The Hospital provides quality health care services to the neighbouring states like Oyo, Kogi, Niger, Osun, and Ekiti. Ilorin is the capital of Kwara State in Nigeria, West Africa. Ilorin coordinates on the globe at $8^{\circ} 30^{\prime} \mathrm{N} 4^{\circ} 33^{\prime} \mathrm{E}$. Ilorin's central location makes it easily accessible from all parts of the country.

\section{Study design}

Ninety-seven patients living with HIV/AIDS were recruited from the Antiretroviral Therapy Clinic of University of Ilorin teaching hospital. Blood samples were collected from all enrolled patients by trained phlebotomists. None of the patients had been on antifungal therapy. In addition, all participants were $\mathrm{HBsAg}$ and anti-HCV negative.

Serum was separated by centrifuging the blood within one hour of collection for at least 15 ' at 2500 revolutions per min (RPM), then transferred into serum aliquot containers and stored at $-20^{\circ} \mathrm{C}$ before being subjected to Aspergillus Galactomannan ELISA.

\section{Sample size calculation}

The sample size for this study was derived using data from a cross-sectional study by Muzamil et al. (10). Therefore, the minimum sample size required for this study was 95 using a 5\% error margin and $95 \%$ confidence interval. However, a total of 97 volunteers were recruited as participants for this study.

\section{Questionnaire and medical history}

Interview-based questionnaires were used to collect participants' socio-demographic variables, while their medical history was assessed from each own hospital folder (upon consent) by their physicians.

\section{Laboratory analytical procedures}

\section{Determination of cluster of differentiation $\left(\mathrm{CD}^{+}\right)$cell count}

Based on the manufacturer's instructions, $\mathrm{CD}^{+}$cell counts in the whole blood were analysed using a Partec ${ }^{\mathrm{TM}}$ CyFlow Analyzer (Sysmex, Norderstedt, Germany) Model SL3. This device is based on the principle of light scattering property (based on dissimilarity in cell size or granularity) and fluorescence of cells following staining with monoclonal antibodies to markers on the cell surface bound to fluorescent dyes. Cell populations of interest were then gathered after identification. Absolute $\mathrm{CD} 4^{+}$cell counts were subsequently analysed using a single-platform technique.

\section{Determination of Serum Aspergillus Galactomannan Expression by ELISA}

The Aspergillus Galactomannan Assay Test is an indirect competition microplate assay for the detection of Aspergillus Galactomannan antigen using specific antibodies, transferring the pre-treated mixtures of the human serum sample and the anti-galactomannan antibodies into the microplates which have been coated with the galactomannan antigen. After the microplate had been incubated and washed, the enzyme labelled antibodies were added. Following a second incubation and washing, Chromogen TMB substrate solution was added to form a color reaction. The absorbance value was determined by a microplate reader at $450 \mathrm{~nm}$ wavelength. The absorbance value has a positive correlation with the galactomannan quantity in the serum sample. Then the concentration of the galactomannan in the human serum can be calculated from the standard curve and the quantitative detection can be performed.

\section{Ethical consideration}

Ethical approval was obtained from the Ethical Review Committee of the University of Ilorin. Informed consent was also given by all participants in accordance with the standards of human experimentation and according to the criteria set by the Helsinki Declaration of 1975, as revised in 2000.

\section{Statistical analysis}

Data obtained from the questionnaire and results of the laboratory analyses were analysed using statistical package for social sciences (SPSS) version 20 California, USA. Data were submitted for descriptive statistics (frequency tables and charts). Chi-square $\left(\chi^{2}\right)$ test was used to determine significant association between the prevalence of Aspergillus Galactomannan antigenemia and sociodemographic variables/risk factors studied. Probability value less than 0.05 were considered significant.

\section{Results}

The socio-demographic data of all the participants in the study population are reported on Table 1. The age range of the participants was $0-79$ years with a mean age of 39.2 years. Out of the 97 participants, 3 were seropositive for the assay and their optical density (OD) readings were $1.967,1.585$ and 1.963 . The concentration of galactomannan antigenemia in the 3 positive samples was estimated at $2.2 \mu \mathrm{g} / \mathrm{L}, 1 \mu \mathrm{g} / \mathrm{L}$ and $2.19 \mu \mathrm{g} / \mathrm{L}$, respectively (Figure 1), while the level of galactomannan index was estimated at 1.1, 0.9 and 1.1, respectively (Figure 2). The sex distribution of galactomannan antigenemia was the highest among females in the age group 21-39, while males in the age group 60-70 presented a higher prevalence.

The medical data of participants enrolled in the study refer to the length (expressed in years) on antiretroviral therapy and CD4+ T cells count (Table 2). Out of the 97 participants, all samples positive for galactomannan antigenemia were obtained from those who had been on antiretroviral therapy for more than 3 years; two out of these participants had a CD4 count level higher than 200 cells $/ \mathrm{mm}^{3}$.

Figure 1 shows the determination curve of galactomannan concentration from OD readings of seropositive samples of HIV/AIDS patients. Out of the $97 \mathrm{HIV} /$ AIDS patients, 3 were positive for the assay and their OD readings were $1.967,1.585$ and 1.963. Using the determination curve, their galactomannan concentration was 
estimated at $2.2 \mu \mathrm{g} / \mathrm{L}, 1 \mu \mathrm{g} / \mathrm{L}$ and $2.19 \mu \mathrm{g} / \mathrm{L}$, respectively. The coloured dots are the seropositive samples.

\section{Aspergillus Galactomannan optical density index determination by ELISA}

Figure 2 shows the level of galactomannan index of positive samples from their OD readings. The 0.5 cut-off OD index, as approved by United States FDA, was adopted. Out of the 97 samples, 3 were seropositive with an OD index of 1.1, 0.9 and 1.1.

\section{Discussion}

Overall prevalence of Aspergillus serum galactomannan antigenemia

Previous studies in Nigeria have used other diagnostic methods, such as fungal culture of the lung tissue to diagnose invasive pulmonary aspergillosis among patients with HIV/AIDS in Nigeria. In this study, detection of galactomannan antigenemia by

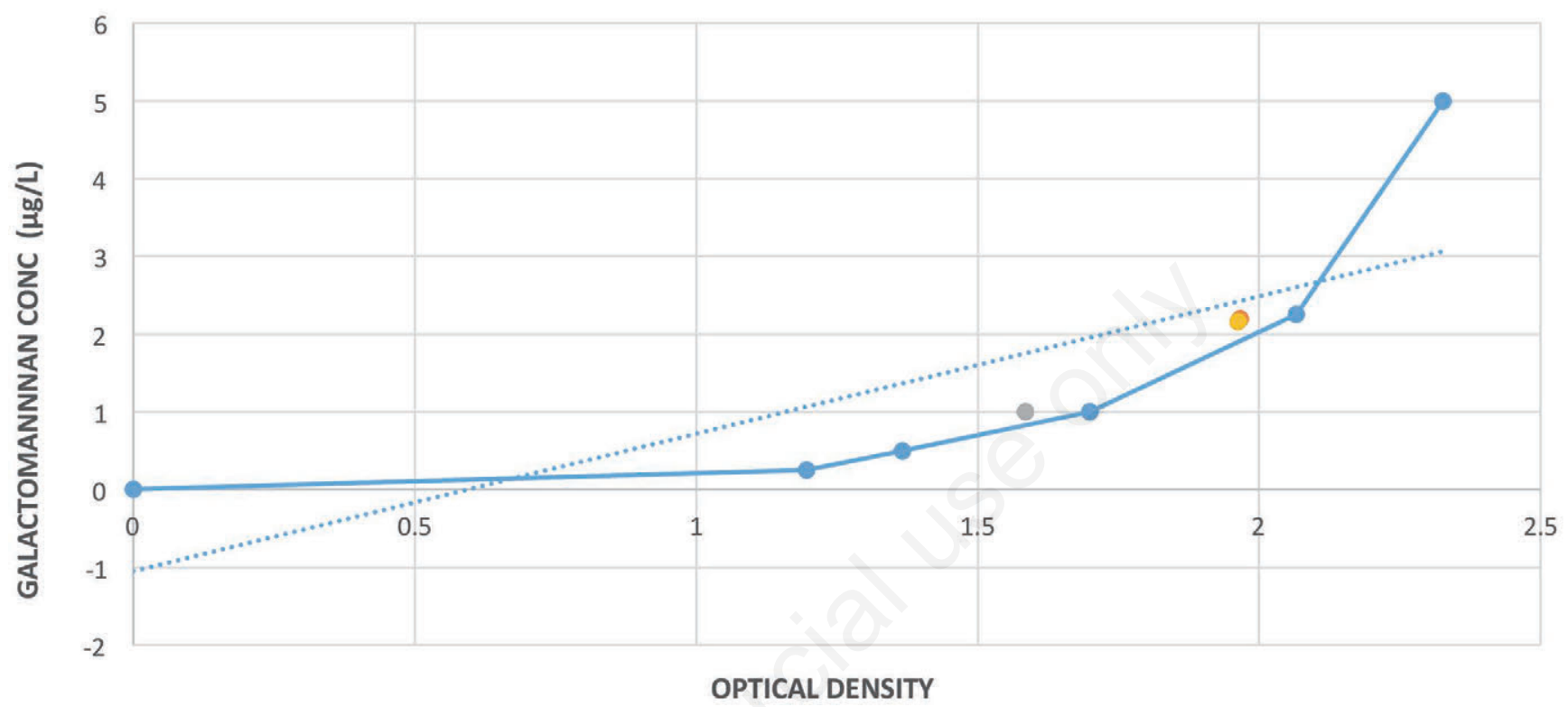

Figure 1. Determination curve of galactomannan concentration from optical density readings of seropositive samples.

Table 1. Distribution of socio-demographic data and galactomannan antigenemia seroprevalence.

\begin{tabular}{|c|c|c|c|c|c|}
\hline Demographics & Positive & Prevalence, \% & Significance & Chi-square $\left(\chi^{2}\right)$ & Total $(\mathrm{n}=97), \mathrm{n}(\%)$ \\
\hline $\begin{array}{l}\text { Age interval } \\
0-19 \\
20-39 \\
40-59 \\
60-79\end{array}$ & $\begin{array}{l}0 \\
2 \\
0 \\
1\end{array}$ & $\begin{array}{c}0 \\
6.7 \\
0 \\
14.3\end{array}$ & $\begin{array}{c}<0.0001 \\
0.0771\end{array}$ & $\begin{array}{l}22.78 \\
3.125\end{array}$ & $\begin{array}{c}10 \\
30 \\
50 \\
7\end{array}$ \\
\hline $\begin{array}{l}\text { Gender } \\
\text { Female } \\
\text { Male }\end{array}$ & $\begin{array}{l}2 \\
1\end{array}$ & $\begin{array}{l}2.9 \\
3.5\end{array}$ & $\begin{array}{l}<0.0001 \\
<0.0001\end{array}$ & $\begin{array}{l}0.681 \\
0.669 \\
\end{array}$ & $\begin{array}{l}69(70.1) \\
29(29.9)\end{array}$ \\
\hline $\begin{array}{l}\text { Residence } \\
\text { Urban } \\
\text { Rural }\end{array}$ & $\begin{array}{l}1 \\
2\end{array}$ & $\begin{array}{l}1.4 \\
8.3\end{array}$ & $\begin{array}{l}<0.0001 \\
<0.0001\end{array}$ & $\begin{array}{l}68.12 \\
6.962\end{array}$ & $\begin{array}{l}73(75.3) \\
24(24.7)\end{array}$ \\
\hline $\begin{array}{l}\text { Education level } \\
\text { Primary } \\
\text { Secondary } \\
\text { Tertiary } \\
\text { None }\end{array}$ & $\begin{array}{l}0 \\
2 \\
0 \\
1\end{array}$ & $\begin{array}{c}0 \\
6.9 \\
0 \\
5\end{array}$ & $\begin{array}{l}<0.0001 \\
0.0001\end{array}$ & $\begin{array}{l}21.806 \\
15.429 \\
\end{array}$ & $\begin{array}{l}19(19.6) \\
29(29.9) \\
29(29.9) \\
20(20.6)\end{array}$ \\
\hline $\begin{array}{l}\text { Occupation } \\
\text { Civil servant } \\
\text { Trader } \\
\text { Farmer } \\
\text { Artisan } \\
\text { Student } \\
\text { Others } \\
\text { Unemployed }\end{array}$ & $\begin{array}{l}0 \\
2 \\
1 \\
0 \\
0 \\
0 \\
0\end{array}$ & $\begin{array}{c}0 \\
5.6 \\
12.5 \\
0 \\
0 \\
0 \\
0\end{array}$ & $\begin{array}{c}<0.0001 \\
0.0455\end{array}$ & $\begin{array}{c}28.658 \\
4.000\end{array}$ & $\begin{array}{c}8(8.2) \\
36(37.1) \\
8(8.2) \\
13(13.4) \\
12(12.4) \\
8.2(8.2) \\
12(12.4)\end{array}$ \\
\hline
\end{tabular}


ELISA was used. To the best of our knowledge, this is the first study in Nigeria investigating Aspergillus serum galactomannan antigenemia among patients with HIV/AIDS. The prevalence of serum galactomannan antigenemia was 3.1\%, lower than that found in a similar study carried out by Adisa et al. (11). In that survey, which reported a prevalence of $46 \%$, a cytological assessment of pulmonary aspergillosis in HIV/AIDS patients was carried out using staining technique such as periodic acid Schiff and hematoxylin-eosin staining.

In order to evaluate the results, the adopted cut-off OD index was 0.5 , as approved by FDA. The same value has been used in a previous study (12).

Galactomannan test is more sensitive than the culture and direct microscopy technique and more specific than the computed tomography scan. Although more invasive techniques, such as histological examination and fungal culture of lung tissue, have been used, Aspergillus galactomannan antigenemia remains the gold standard test for rapid diagnosis of IPA in conjunction with clinical evidences and host factors (13).

\section{Prevalence of Aspergillus serum galactomannan antigenemia by age of among HIV/AIDS patients}

Age distribution of serum galactomannan antigenemia shows a higher prevalence (14.3\%) in the age group 60-79, in agreement with the findings of Wakayama et al. (14) These might be attributable to the easy adherence and germination of Aspergillus spp. in the epithelial surface of the lower respiratory tract connected with the old age. The age group 20-39, that constitutes a large part of the country's labour force, ranks second, as already reported by Adisa et al. (11) However, this observation might be due to the high prevalence of HIV/AIDS among this age group.

\section{Prevalence of Aspergillus serum galactomannan antigenemia by gender of HIV/AIDS patients}

Gender distribution of serum galactomannan antigenemia among HIV/AIDS patients shows a prevalence of 3.6\% and $2.9 \%$ from males and females, respectively, as reported in Table 1.

These findings are consistent with those reported by Kuo-Shao

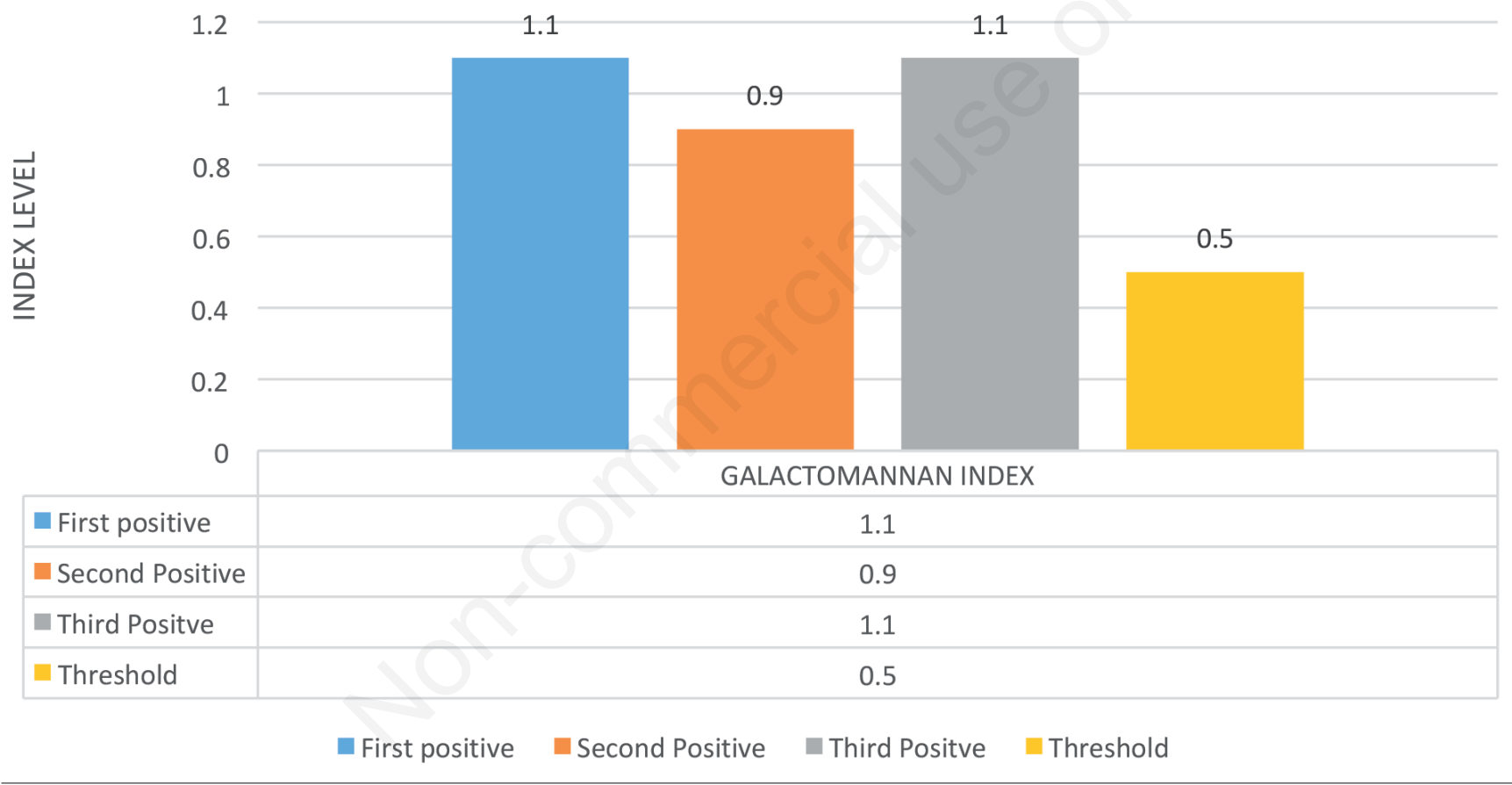

Figure 2. Determination of galactomannan index from optical density readings of positive samples.

Table 2. Prevalence of Aspergillus Galactomannan antigenemia from patients' medical history.

\begin{tabular}{|c|c|c|c|c|c|}
\hline Medical history & Positive & Prevalence, \% & Significance & Chi-square $\left(\chi^{2}\right)$ & Total $(\mathrm{n}=97), \mathrm{n}(\%)$ \\
\hline $\begin{array}{l}\text { Years of ART } \\
<1 \\
1-3 \\
>3\end{array}$ & $\begin{array}{l}0 \\
0 \\
3\end{array}$ & $\begin{array}{c}0 \\
0 \\
4.4\end{array}$ & 0.3622 & 0.830 & $\begin{array}{c}6(6.2) \\
23(23.7) \\
68(70.1)\end{array}$ \\
\hline $\begin{array}{l}\text { CD4 count }\left(\text { cells } / \mathrm{mm}^{3}\right) \\
<200 \\
200-300 \\
301-400 \\
401-500 \\
>500\end{array}$ & $\begin{array}{l}1 \\
0 \\
0 \\
2 \\
0\end{array}$ & $\begin{array}{c}5.9 \\
0 \\
0 \\
11.1 \\
0\end{array}$ & 0.2236 & 5.689 & $\begin{array}{l}17(17.5) \\
17(17.5) \\
12(12.4) \\
18(18.6) \\
33(34)\end{array}$ \\
\hline
\end{tabular}


et al. (15) The fact that men are more likely to get in contact with moulds of Aspergillus spp. is due to their outdoor activities, such as farming, building and milling which involve a higher risk of inhaling spores. Conversely, more females resulted to be seropositive for the assay than males; this discrepancy might be due to the fact that females constitute a larger number of HIV/AIDS populations in Nigeria. Additionally, females are more exposed to Aspergillus spp. because they are generally engaged in outdoor activities, such as storing and drying of grains.

\section{Prevalence of Aspergillus serum galactomannan antigenemia by residence of HIV/AIDS patients}

A higher prevalence of $8.3 \%$ was observed in HIV/AIDS patients residing in rural areas compared to those residing in urban areas. This might be due to the activities that rural residents engaged, such as farming; additionally, and some houses they live in are old or made of mud. Their level of hygiene might also be a reason for such prevalence. These environmental conditions increase the chances of exposure to fungal spores, particularly Aspergillus spp.

\section{Prevalence of Aspergillus serum galactomannan antigenemia by educational level}

A $6.9 \%$ prevalence was found among HIV/AIDS patients that had secondary school level of education. This might be due to the lack of knowledge on fungi, particularly mould-like fungi, such as Aspergillus spp., Fusarium spp. and Pennicillium spp., and the lethality of the diseases they can cause if inhaled or ingested. Such ignorance reduces the possible implementation of preventive measures, thus increasing their chances of exposure to Aspergillus spp. spores.

\section{Prevalence of Aspergillus serum galactomannan antigenemia by occupation of HIV/AIDS patients}

A $12.5 \%$ prevalence was detected among HIV/AIDS patients who are farmers by occupation, according to the finding reported by Syed et al. (16). This prevalence might be related to the high probability of inhaling moulds from the soil, dust particles or farm products such as tubers and grains. Nevertheless, 2 out of the 3 HIV/AIDS seropositive patients were traders: this discrepancy might be the result of a higher number of traders compared to farmers in the study population. However, traders, particularly those involved in sale of foods, feeds, and saw dusts can inhale Aspergillus spp. spores during packaging, storing and transportation.

\section{Prevalence of Aspergillus galactomannan antigenemia in relation to $\mathrm{CD} 4 \mathrm{~T}$ cell count}

In this study, a prevalence of $11.1 \%$ was seen from HIV/AIDS patients with CD4 T cells count between $400-500$ cells $/ \mathrm{mm}^{3}$, in agreement with Adejumo et al. (17) who reported a case of IPA in a patient with a CD4 count of 863 cells $/ \mathrm{mm}^{3}$. However, this finding contradicts that of Holding et al. (18) who reported IPA in patients with less than $>200$ cells $/ \mathrm{mm}^{3}$. The findings in these studies might explain other disease conditions, such as neutropenia, which is another risk factor for IPA. Probably, the most prevalence in patients with CD $4>400$ cells $/ \mathrm{mmc}$ is due to the rapidly increase of CD4 count in patients responding to antiretroviral therapy (the Immune Reconstitution Inflammatory Syndrome).

\section{Comparison of symptoms related to IPA within study population}

In this study, 57 out of 97 HIV/AIDS patients experienced at least one symptom of IPA: fever $53.6 \%$; cough $24.7 \%$; chest pain
$10.3 \%$ and breathing difficulty $7.2 \%$. Fever and cough were common among HIV/AIDS patients positive for the assay; the less frequent symptom relating to IPA was chest pain. These symptoms, particularly fever and cough, are commonly observed at early stages of IP (5). These findings are in agreement with those reported by Adejumo et al. (17) and Blot et al. (19).

\section{Relationship between risk factors and galactomannan assay seropositivity}

HIV/AIDS was the major risk factor for invasive pulmonary aspergillosis in this study, as in previous studies carried out on invasive pulmonary aspergillosis. There are other risk factors for invasive pulmonary aspergillosis such as neutropenia, haematological malignancy and corticosteroid therapy; however, they were not used in this study. The socio-demographic data, which include age, sex, occupation, residence, and medical history such as years on antiretroviral therapy and level of CD4 count were analysed as possible risk factors for IPA in this study but they were not statistically significant, although previous studies have shown that they could play a role in invasive pulmonary aspergillosis (10-19).

\section{Conclusions}

Aspergillus serum galactomannan assay remains a key approach for the rapid diagnosis of IPA in HIV/AIDS patients that may be averted by an expedient use of galactomannan antigenemia. However, an early diagnosis of IPA may be possible because galactomannan assay may yield positive results needed to set a proper therapeutic management of IPA before continuous deterioration of an immunocompromised patient complicates infection by Aspergillus species. Galactomannan is also produced by other filamentous fungi such as Fusarium spp, Penicillum spp., and Alternaria spp., thus the index of galactomannan antigenemia throws in a red flag to intensify therapeutic intervention in such cases. It has been noted that age, sex, residence, occupation, educational level, CD4 count and years of ART have no effect on galactomannan production, and there is no correlation between these variables and galactomannan antigenemia: apparently this has to be the case because galactomannan production is a function of a fungi and it is not influenced by any this factors, although Aspergillus galactomannan may be influenced by the immune status of an afflicted individual, About CD4 we assume that the rapidly increase of CD4 count could be reactivate the silent fungal infection. Further studies should be carried out on the level of cross-reactivity of Aspergillus galactomannan antigenemia with other fungal species.

\section{References}

1. Kousha M, Tadi R, Soubani A. Pulmonary aspergillosis: a clinical review. Eur Respir Rev 2011;20:156-74.

2. Zmeili O, Soubani A, Pulmonary aspergillosis: a clinical update. Q J Med 2007;100:317-34.

3. Addrizzo-Harris D, Harkin T, McGuinness G, Naidich D, Rom W. Pulmonary Aspergilloma and AIDS: A Comparison of HIVInfected and HIV-Negative Individuals. Chest 1997;111:612-8.

4. Trautmann M, Ruhnke M, Held T, Weinke T. Complicated tuberculosis and residual disease. Immunobiology 1994;191: 344-50

5. Annaissie E, McGinnis M, Pfaller M. Clinical Mycol 2009;2:271-96. 
6. Pfeiffer C, Fine J, Safdar N. Diagnosis of invasive aspergillosis using a galactomannan assay: a meta-analysis. Clin Infect Dis 2006;42:1417-27.

7. Barton R. Laboratory Diagnosis of Invasive Aspergillosis: From Diagnosis to Prediction of Outcome. Scientifica 2013:1-29.

8. Zdenek R, Iva K, Martina T, et al. Galactomannan detection in bronchoalveolar lavage fluid for the diagnosis of invasive aspergillosis in patients with hematological diseases - the role of factors affecting assay performance. Int $\mathrm{J}$ Infect Dis 2011;e874-81.

9. Berkeley L, Dixon C, Bala S. Detection of Galactomannan in Serum by Platelia ${ }^{\mathrm{TM}}$ Aspergillus Enzyme-linked Immunosorbent Assay. Division of Special Pathogen and Transplant Products. Biomarker Qualification. 2011.

10. Muzamil J, Guru F, Hakim A, Nabi F. Invasive Pulmonary aspergillosis in oncological setting with use of newer vascular endothelial growth factor receptor inhibitor. Commun Acquir Infect 2016;3:16-23.

11. Adisa J, Mohammed B, Egbujo E, Bukar M. Cytologic Assessment of Pulmonary Aspergillosis in Immunocompromised Subjects in Maiduguri North Eastern, Nigeria. J Med Med Sci 2013:237-40.

12. Musher B, Fredricks D, Leisenring W, et al. Aspergillus galactomannan enzyme immunoassay and quantitative PCR for diagnosis of invasive aspergillosis with bronchoalveolar lavage fluid. J Clin Microbiol 2004;42:5517-22.

13. Hoenigl M, Pratters J, Spiess B, et al. Performance of galactomannan, beta-d-glucan, Aspergillus lateral flow device, conventional culture and PCR tests with bronchoalveolar lavage fluid for diagnosis of invasive pulmonary aspergillosis. J Clin Microbiol 2014;52:2039-45.

14. Wakayama M, Shimodaira K, Nakayama L. Age-related analysis on the prevalence of invasive fungal infections from autopsy records in Toho University. Int Soc Hum Anim Mycol 2012;C16-1.

15. Kuo-Shao S, Ching-Fang T, Chih-Cheng C. Galactomannan Testing and the Incidence of Invasive Pulmonary Aspergillosis: A 10-Year Nationwide Population-Based Study in Taiwan. PloS One 2016;11:e0149964.

16. Syed A, Panta P, Shahid I. Invaasive Aspergillosis Associated with a Foreign Body. Case Rep Pathol 2015:875168.

17. Adejumo A, Aidoo C, Cosmina Z, Tjack S. Invasive pulmonary aspergillosis in HIV patient with high CD4 count. Am J Case Rep 2009;10:103-6.

18 Holding J, Dworkin S, Wan T, et al. Aspergillosis among People Infected with Human Immunodeficiency Virus: Incidence and Survival. Clin Infect Dis 2009;31:1253-7.

19. Blot S, Taccone F, Van den Abeele A, et al. A clinical algorithm to diagnose Invasive pulmonary aspergillosis in critically ill patients. Am J Respir Crit Care Med 2012;186:56-64. 